\title{
Kung Paano Ako Natutong Bumasa ng Pelikula
}

\author{
Paul Alcoseba Castillo \\ University of Santo Tomas
}

Nagsimula ang hilig ko sa pag-unawa sa mga pelikula nang minsang ginamit ni Propesor Michael M. Coroza sa Gradwadong Paaralan ng Unibersidad ng Santo Tomas ang Titanic (James Cameron, 1997) bilang halimbawa ng pagbasa sa teksto. Iniukol ng propesor ang atensyon sa dulong eksena ng paghagis ng kuwintas pabalik sa dagat at sa binitawang linya ng protagonistang si Rose na "A woman's heart is a deep ocean of secrets" na ayon sa pagpapaliwanag ay maaaring susi sa buong pelikula. Ipinatatanaw nito kung paanong lumulubog ang kalalakihan sa kanilang pagkahumaling sa kababaihan sa kabila ng tila dominasyon ng una sa huli, at inilalarawan ito ng barkong simbolo ng mapagmalaking lalaki na nilamon lamang ng Karagatang Atlantiko na, gaya ng brilyanteng Heart of the Ocean, ay kumakatawan sa babae.

Ito ang dahilan kung bakit sinimulan ko ang personal na blog pampelikula na Kung Sine Sine Lang noong 2014 na dapat ay ehersisyo lamang sa closed reading ng mga tekstong pampanitikan o iyong tinatawag na New Criticism dahil malikhaing pagsulat ang pinagmumulan kong disiplina. Bilang isang instruktor sa unibersidad, naging bahagi rin ang maikling anekdota tungkol sa Titanic sa introduksiyon ko sa sining ng pelikula sa pagtuturo ng Art Appreciation, na kursong sa ilalim ng General Education sa antas ng kolehiyo. Ngunit lagi kong idinaragdag na ang panunuring pampelikula ay hindi nagtatapos sa closed reading, na ang paraang ito ay nagbubukas sa iba't 
ibang teoryang pilosopikal at kultural o pampanitikan. At gaya sa halimabawang Titanic, pumapasok na ang tunggalian ng mga kasarian, politikal, at ekonomiyang kalagayang umiiral sa pagitan ng mga tauhan at maging sa kaligiran ng obra.

Bagaman kumukuha na ako ng master's nang mabuksan ako sa idea ng pagsusulat hinggil sa pelikula, matagal na akong nanonood ng mga pelikula. Gayong lumaki ako sa panonood ng mga Hollywood films, kumikiling ang panonood ko sa mga Filipinong pelikulang independent. Nasa kolehiyo na ako nang matuklasang "indie" pala ang dalawang takdang papanoorin para sa klase: Ang Daan Patungong Kalimugtong ni Mes de Guzman at ang Maicling Pelicula nañg Ysang Indio Nacional ni Raya Martin. Nabuksan din ako sa papausbong pa lamang noon na Cinemalaya Philippine Independent Film Festival kaya naman sinusubok ko hanggang ngayon ang pagtangkilik sa mga katulad na film festival. Inaabangan ko maging ang mga pelikulang usap-usapang ilalabas o kaya'y nagsipagwagi sa mga prestihiyosong patimpalak sa abroad. Lahat ng ito, dinarayo ko sa mga venue gaya ng Cultural Center of the Philippines, mga micro-cinema, at iilang sinehan na inilaan ng mga mall.

Mahalagang may ganitong bias laban sa produkto ng mainstream films dahil maaaring sa indie matatagpuan ang mga sineng labas sa pormularyo ng malalaking studio. Kaya mula 2014, inilalaan ko ang pagsusulat hinggil sa mga pelikulang indie na matutunghayan lamang sa mga film festival dahil dito, para sa akin, pinakasagana ang mga sine natin na masasabing dapat ay mahusay sa lahat ng mahuhusay. Gayunman, pinipili ko pa rin aling pelikula ang gagawan ng kritisismo o kaya'y pagbasa. Kung may anim hanggang walong kabilang sa kompetisyon, may dalawa o tatlong obrang hindi ko isusulat kahit napanood. Dahil bukod sa pagbibigay ng rebyu kung maayos o hindi, kung maganda o pangit ang likha ng filmmaker, kinikilatis ko rin tuwing nagsusulat ang silbi ng bawat elementong piniling ipasok sa pelikula at kung paano nito naipamamalas ang isang bagong idea sa tagapanood.

Sa ganitong pagtingin, kinakailangang nakalalampas ang isang pelikula sa pinakamababang kahingian ng organikong kaisahan, iyong walang nasasayang na eksena't elemento sa kabuuan ng ipinahihiwatig na bisyon ng direktor. Kung hindi na natutugunan ng sine ang antas na ito, hindi ko 
na maaasahang makapaglalahad ito ng higit na maayos na kahulugan para sa akin, at higit sa lahat, sa payak na tagapanood sa sinehan. Kung ihahambing ko ito sa pag-aaral at pagbabasa ng panitikan, nararapat na pagkatapos ng closed reading, nagsisimulang mailugar ang obra sa konteksto ng panahong naipalabas ito at maging sa buhay ng filmmaker.

Nais kong linawin na nakalaan ang pagsusulat ko hinggil sa mga pelikulang indie, na para sa akin ay isang terminong hindi patungkol sa budget. Nagiging indie ang pelikula dahil sa kakulangan ng mga sinehang nagbibigay ng suporta para maitawid sa tagapanood ang likha ng filmmaker sa kabila ng kompetisyon ng mga kanluraning sine, lalong-lalo iyong mula Hollywood. Dahil dito, nilalayon ng sinimulan kong blog na maipatanaw sa Filipinong manonood kung ano ang dapat nilang asahan sa mga inilalabas na bago ng mga maituturing nilang "hindi kilalang" mga aktor o direktor. Kung nakapanood naman at hindi maunawaan ang natunghayan, ang pagbasa ko ay naroon para linawin ang ilang mahahalagang punto sa pelikula.

Naniniwala akong mahalaga ang ibinibigay kong pagpapaliwanag sa kahulugan at bisa ng obra, pelikula o panitikan, dahil ito ang maglalapit sa tao at sa sining. Dahil sa ngayon, may sapantaha ang mga nagbabasa ng panunuring pampelikula, lalo kung nasa anyo ng rebyu, na ang tanging silbi nito ay sabihin kung dapat o hindi dapat panoorin ang isang pelikula. Dapat sana'y pinagbibigyan ang anumang ipapalabas at hindi lamang nadidiktahan ang panlasa ng manonood batay sa opinyon ng isang kritiko. Sa ganitong paraan matututo kung paano dapat tangkilikin ang sine at iba pang uri ng sining sa Filipinas. 